\title{
Significance of transvaginal sonographic assessment of cervical length before induction of labour
}

\author{
Shreya M. S., Savitha C.* \\ Department of Obstetrics and Gynecology, Rajarajeswari Medical College, Kambipura, Bangalore, Karnataka, India \\ Received: 29 June 2018 \\ Accepted: 27 July 2018 \\ *Correspondence: \\ Dr. Savitha C., \\ E-mail: drshreyatharun@gmail.com \\ Copyright: (C) the author(s), publisher and licensee Medip Academy. This is an open-access article distributed under \\ the terms of the Creative Commons Attribution Non-Commercial License, which permits unrestricted non-commercial \\ use, distribution, and reproduction in any medium, provided the original work is properly cited.
}

\begin{abstract}
Background: The traditional method of predicting whether an induced labor will result in successful vaginal delivery is based on pre-induction favourability of cervix as assessed by bishop score. However, this method is limited by subjectivity and reproducibility and though done in all the patients prior to induction of labour, several studies have demonstrated poor correlation between Bishop score and outcome of labor. Currently assessment of cervical status by sonographically at term in induction of labor is most accurate and highly reproducible compared to Bishop score.

Methods: This study was carried out in a tertiary care teaching institute in Karnataka. 180 pregnant women at or beyond 37weeks who were planned for induction, Bishop score assessment of cervix and cervical assessment by ultrasound such as cervical length (CL) was done one day prior to induction. Induction was with 0.5mg PGE2gel. Maximum 3 induction were carried out over a period of $24 \mathrm{hrs}$. Primary outcome of the study was the onset of active labor.

Results: Amongst 160 pregnant women who were induced (20 women were excluded has they underwent LSCS for some other reasons during latent phase) cervical length by sonography $<2 \mathrm{~cm}$ were 14 none had failed induction. Amongst 180 pregnant women who were induced cervical length $<2 \mathrm{~cm}$ in 14 all had Bishop score $>4$.

Conclusions: Transvaginal sonographic measurement of cervical length was evaluated in predicting response to induction. $\mathrm{CL}<2 \mathrm{~cm}$ was associated with greater incidence of successful labor induction. These results show the CL has significant role in predicting outcome of labor.
\end{abstract}

Keywords: Bishop score, Cervical length, Induction of labor, Transvaginal sonography

\section{INTRODUCTION}

Induction of labour is the most common intervention in modern obstetrics. ${ }^{1}$ Induction of labour is defined as iatrogenic stimulation of uterine contraction to accomplish delivery prior to the onset of spontaneous labour. ${ }^{2}$ Induction of labour is indicated when benefits to mother or the fetus outweigh those of continuing the pregnancy such as postdated pregnancy, PROM, fetal growth restriction or medical disorders with pregnancy and fetal demise etc. ${ }^{3}$ Induction of labor is non spontaneous initiation of uterine contraction that results in progressive cervical effacement, dialatation of cervix and descent of presenting part leading to vaginal delivery of healthy baby (Failed induction- there is no universally accepted definition for failed induction). ${ }^{4}$ It should perhaps be reserved for those cases where the cervix does not dialate beyond $3 \mathrm{~cm}$ despite adequate and appropriate oxytocic stimulation. ${ }^{4}$ Kumaran A et al diagnose it when a patient who is induced does not enter the active labour despite of adequate management for 12 hours. $^{5}$

Cervical status is one of the most important factors of predicting likelihood of successful induction of labour. ${ }^{6}$ Traditionally, pre-induction cervical assessment is based on digital examination of cervix using Bishop score 
which is simple and easy to perform. ${ }^{7}$ One of the most common labour ward problems is difference of digital assessment of cervix between members of medical team. The reason behind this conflict is subjective nature of digital examination of cervix, especially the assessment of the cervical length. ${ }^{8}$ The Bishop's score has a poor predictive value for the outcome of induction of labour due to the controversy in assessment of cervical nature by different examiners. ${ }^{9,10}$ The supravaginal portion of the cervix makes up about $50 \%$ of cervical length.This portion of cervix is difficult to estimate digitally and it makes assessment highly subjective. ${ }^{11}$ Transvaginal ultrasound allows visualization of cervix beyond closed external os and measures the cervical length accurately without much inter-observers variation. ${ }^{8,12,13}$ Therefore, more recently several authors have tried to find a more objective and uniform method of assessment of cervical length using transvaginal sonography for prediction of outcome of labour induction. ${ }^{7,14-17}$ So this was designed to compare the cervical length measured by TVS with modified Bishop's score for cervical assessment before induction of labour.

\section{METHODS}

This prospective observational study was carried out on 180 pregnant ladies admitted in labor room for induction of labor. Women with singleton pregnancy at or beyond 37 weeks, vertex presentation, live fetus, intact membranes with no vaginal bleeding were included. Women with previous ceaserean section, APH and CPD were excluded from the study. After careful history and general examination, digital vaginal examination was done to evaluate the cervix and to record the modified Bishop's score, followed by TVS to record the cervical length in $\mathrm{mm}$ for each patient.

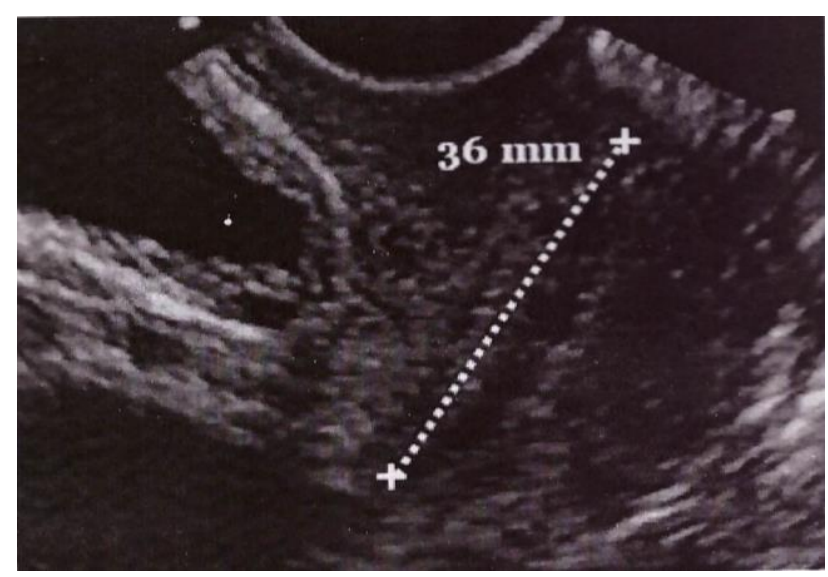

Figure 1: Ultrasonographic image that shows a longitudinal section of cervix.

The vaginal probe was inserted under visualization after evacuation of bladder. The midline saggital plane of the cervix was localized, and then the probe was pulled back until the lightest touch provided a good image of the cervical canal with fixation of the internal os in the proximal one third of the image. All TVS examination were done by an experienced sonographer, who was blinded to the patient clinical data. The standard anatomical landmark during examination was the presenting fetal part, urinary bladder, internal and external os and the cervical canal.

Cervical length was considered the hyperechoic line extending from internal os to external os. The internal os was identified as a dimple or a small triangle against the hypoechoic background of amniotic fluid. Cervical length was measured 3 times and the mean cervical length was recorded. ${ }^{18}$

Induction of labour was done after the initial vaginal examination, when the modified Bishop's score was evaluated, induction was done with $0.5 \mathrm{mg}$ of PGE2 gel which was instilled intracervically. There was universal electronic fetal monitoring for women undergoing labour induction. Patient was reassessed after every $8 \mathrm{hrs}$ and if she did not exhibit regular uterine contraction and cervical changes, PGE2 gel 2nd and 3rd dose was instilled accordingly. Maximum 3 induction were carried out over a period of $24 \mathrm{hrs}$. Primary outcome of the study was the onset of active labour i.e. onset of regular uterine contractions and cervical dilatation of $3 \mathrm{~cm}$ or more.

Table 1: Modified Bishop score.

\begin{tabular}{|llll|} 
Factors & 0 & 1 & 2 \\
Dilatation & $<1.5$ & $1.5-3$ & $>3$ \\
\hline Station & -2 & -1 & 0 \\
\hline Position & Posterior & Middle & Anterior \\
Effacement & $\begin{array}{l}1.5 \text { or } \\
\text { more }\end{array}$ & Intermediate & $\begin{array}{l}0.5 \text { or } \\
\text { less }\end{array}$ \\
\hline Consistency & Firm & Intermediate & Soft \\
\hline
\end{tabular}

\section{Statistical analysis}

Data were collected and statistical package for the social sciences (SPSS for windows 10) was used for the data compilation and statistical analysis. The categorical data was analysed using chi square or Fischer exact test. Results were considered significant when $\mathrm{p}$ value was less than or equal to 0.05 for any of the test used.

\section{RESULTS}

Total number of case studied were 180 , all patients were induced according to the protocol after assessing the cervical status by transvaginal ultrasound and by modified bishop score.

Table 2: Age distribution of study population.

\begin{tabular}{|ll|}
\hline Age & $\mathbf{N}=180$ \\
\hline $20-25$ & $60(33.3 \%)$ \\
\hline $26-34$ & $90(50 \%)$ \\
\hline$>35$ & $30(16.6 \%)$ \\
\hline
\end{tabular}


Table 3: Parity distribution of study population.

\begin{tabular}{|llll|} 
Gravida & $\mathbf{N}=160$ & $\begin{array}{l}\text { Active labor } \\
\mathbf{N}=124\end{array}$ & $\begin{array}{l}\text { Failed induction } \\
\mathbf{N}=36\end{array}$ \\
\hline Primi & 110 & $76(69 \%)$ & $34(31 \%)$ \\
\hline Multi & 50 & $48(96 \%)$ & $02(4 \%)$ \\
\hline
\end{tabular}

Parity distribution in Table 3, 180 women were enrolled in the study, but number of cases analysed were 160 as 20 women went on to have LSCS in latent phase of labor due to other reasons.

Table 4: Observation of result in comparison of cervical length and response to induction.

\begin{tabular}{|llll|}
\hline $\begin{array}{l}\text { Cervical } \\
\text { length } \\
\mathrm{N}=160\end{array}$ & $\mathbf{3} \mathrm{cm}$ & $\mathbf{3}-2 \mathrm{~cm}$ & $<2 \mathrm{~cm}$ \\
$\mathrm{~N}=98$ & $\mathrm{~N}=98$ & $\mathrm{~N}=14$ \\
\hline $\begin{array}{l}\text { Active phase } \\
\mathrm{N}=124\end{array}$ & $20(40 \%)$ & $90(87.7 \%)$ & $14(100)$ \\
\hline $\begin{array}{l}\text { Failed } \\
\text { induction } \\
\mathrm{N}=36\end{array}$ & $28(60 \%)$ & $08(12.3 \%)$ & 0 \\
\hline $\mathrm{P}$ value $<0.001$ & & & \\
\hline
\end{tabular}

Out of 160 patients, 14 had cervical length less than $2 \mathrm{~cm}$ out of which none had failed induction, when cervical length was between 3 to $2 \mathrm{~cm}$ in 98 patients only 8 $(12.3 \%)$ had failed induction and $90(87.7 \%)$ of them entered into active phase. This result shows the sonographic assessment of cervical length has significant role in predicting outcome of labor, shorter the cervical length greater is the incidence of success of labor induction.

Table 5: Observation of result in comparison of Bishop score and response to induction.

\begin{tabular}{|lll|}
\hline Bishop score, $\mathrm{N}=160$ & $>4, \mathrm{~N}=120$ & $<4, \mathrm{~N}=40$ \\
\hline Active phase, $\mathrm{N}=124$ & $114(95 \%)$ & $10(25 \%)$ \\
\hline Failed induction, $\mathrm{N}=36$ & $6(5 \%)$ & $30(75 \%)$ \\
\hline $\mathrm{P}$ value $<0.001$ & & \\
\hline
\end{tabular}

Table 6: Observation of result in comparison of cervical length and bishop score.

\begin{tabular}{|llll|}
\hline $\begin{array}{l}\text { Cervical length } \\
n=180\end{array}$ & $\begin{array}{l}>3 \mathrm{~cm} \\
\mathrm{n}=58\end{array}$ & $\begin{array}{l}3-2 \mathrm{~cm} \\
\mathrm{n}=108\end{array}$ & $\begin{array}{l}<2 \mathrm{~cm} \\
\mathrm{n}=14\end{array}$ \\
\hline $\begin{array}{l}\text { Bishop score } \\
<4, \mathrm{n}=45\end{array}$ & $33(60 \%)$ & $12(20 \%)$ & 0 \\
$\begin{array}{l}\text { Bishop score } \\
>4, \mathrm{n}=135\end{array}$ & $25(40 \%)$ & $96(80 \%)$ & $14(100)$ \\
\hline
\end{tabular}

Out of 160 patients, 120 had Bishop score more than 4 out of which $114(95 \%)$ of them entered into active phase and $6(5 \%)$ had failed induction and 40 had Bishop score less than 4 out of which $30(75 \%)$ had failed induction and $10(25 \%)$ of them entered into active phase. This result shows the Bishop score more than 4 had greater incidence of successful labor induction.
Out of 180 patients, when CL was less than $2 \mathrm{~cm}$ (14) all had Bishop score $>4$. When CL was more than $3 \mathrm{~cm}(58)$, $33(60 \%)$ had Bishop score less than 4 and $25(40 \%)$ had Bishop score greater than 4 . This result shows that CL is a good predictor of cervical maturation.

\section{DISCUSSION}

Labor induction is a day to day procedure in modern obstetrics. It is gaining even more importance when it comes to terminate pregnancies which have one or more risk factors where it is not preferred to wait till term for example in pre-eclampsia, intrauterine growth restriction, oligohydramnios etc. This is important not only for the obstetrician who is managing the case but also for the patient and her relatives who are giving consent to undergo the process of induction. They need to be explained the chances of failure of procedure, need for reinduction and need for operative delivery in cases of failed induction.

Cervical assessment was first described by bishop's score in 1964 and in most of the units cervix is assessed digitally prior to induction. Various modification of bishop score but inspite of being the most widely used method for cervical assessment, bishop score has a number of drawbacks which has generated the need to develop a better system that is more objective and reproducible. The main drawback is that it is highly subjective and has shown that it is a poor predictor of labor induction outcome. Also, the length of the cervix cannot be measured precisely by digital examination and other parameters that are included in the assessment such as consistency and position of the cervix are to some extent subjective and impressive. In addition to its subjectivity bishop score has wide inter and intra observer variation..$^{8-11}$

Present study showed that sonographic assessment of cervical length successfully predicted cervical maturation. Ultrasound has specific advantages over bishop score. It causes less discomfort for the patient. It can assess full cervical length and status of internal os without invading endocervical canal and hence is less invasive, it is more objective, and findings can be documented by taking a picture, also the findings are reproducible other coexisting finding like compound presentation and occult chord presentation if present can be documented which can be easily missed by doing just a digital examination.

In present study, the best cut off points for successful induction were $20 \mathrm{~mm}$ for the cervical length measured by TVS and for the modified Bishop's score, when the cervical length was $<20 \mathrm{~mm}$, and the modified Bishop's score was $>4$, the possibility of successful induction was increased. In Gomez et al. found that the best cut off points for predicting successful induction were $24 \mathrm{~mm}$ for cervical length measured by TVS and 4 for the modified Bishop's score. ${ }^{19}$ 
Tan et al concluded that TVS was significantly less painful than digital examination and bith cervical length and modified Bishop's score were predictors of the success of induction with optimal cut off points of $20 \mathrm{~mm}$ for the cervical length and $>5$ for the modified Bishop's score, also, they concluded that cervical length measured by TVS had superior sensitivity $(80 \%$ versus $64 \%)$ than the modified Bishop's score. ${ }^{20}$

Yang et al found that the cervical length of $3 \mathrm{~cm}$ or less had $75 \%$ sensitivity and $83 \%$ specificity, also, they found that there was a significant relationship between successful labour induction and cervical length, but not the modified Bishop' score. ${ }^{16}$

Pandis G et al in a multicentric study undertaken in 240 women undergoing induction of labor, cervical length by ultrasound was compared with bishop's score in the prediction of successful vaginal delivery. ${ }^{7}$ In a similar study by Vonda ware concluded that both bishop score and cervical length showed linear co- relation with duration. ${ }^{13}$

Watson et al examined 109 women before induction and reported a significant association between sonographically measured cervical length and Bishop's score; however, neither of the two provided useful prediction of the length of the latent phase of labour. ${ }^{21}$

Gonen et al examined 86 women before induction and reported significant association between both the Bishop score and sonograhically measured cervical length with successful induction and the induction to delivery interval. $^{22}$

Ware and Raynor examined 77 women before induction and found that both the Bishop score and sonograhically measured cervical length predicted induction to delivery interval and likelihood of vaginal delivery. ${ }^{23}$

\section{CONCLUSION}

Sonograhically measured cervical length was evaluated in predicting response to induction, which can be achieved easily and with minimal discomfort to the patients, provides a useful prediction of the likelihood of successful labour induction. Maximum number of successful induction is seen in the age group of 20-30yrs. Also, multigravida had significantly high number of successful inductions. Cervical length when measured by USG revealed that shorter cervical length was associated with greater incidence of successful labor induction. There was no failed induction in subgroup of cervical length less than $2 \mathrm{~cm}$ obtained by USG. Bishop score was greater than 4 when CL was less than $2 \mathrm{~cm}$. This shows that shorter CL are good predictors of successful induction. This result shows the CL is a good predictor of cervical maturation.

\section{Funding: No funding sources}

Conflict of interest: None declared

Ethical approval: The study was approved by the Institutional Ethics Committee

\section{REFERENCES}

1. Royal College of obstetrics and Gynecologists (RCOG). Induction of labour. Evidence based clinical guide line number 9. London: RCOG clinical support unit. 2001.

2. Martin J A, Hamilton B E, Sutton PD, et al. Births: Final data for 2002. NATL Vital Stat Rep. 2003;52:1.

3. Anish K, Vanita S, Rashmi B, Aggarwal N. Preinduction sonographic assessment of the cervix in the prediction of successful induction of labour in nulliparous women. Australian New Zealand J Obstet Gynaecol. 2007;47:389-93.

4. Saanchez-Ramos L, Delke. Induction of labour and pregnancy termination for fetal anomaly. James DK, Steer PJ, Weiner CP, Gonik B. High risk pregnancy management options, $3^{\text {rd }}$ ed. W.B. Saunders, London; 2006:1392-495.

5. Arulkumaran S, Gibb DM, TambyRaja RL, Heng SH, Ratnam SS. Failed induction of labour. Aust. NZ J Obstet Gynecol. 1985;25:190-193

6. Baacke KA, Edward RK. Pre-induction cervical assessment. Clin Obstet Gynecol. 2006;49:564

7. Pandis G, Papageorghiou AT, Ramanathan VG, Thompson MO, Nicolaides KH. Pre-induction sonographic measurement of cervical length in prediction of successful induction of labour. Ultrasound Obstet Gynecol. 2001;18:623-28.

8. Jackson GM, Ludmir J, Bader TJ. The accuracy of digital examination and ultrasound in the evaluation of cervical length. Obstet Gynecol. 1992;79:214-8.

9. Dhall K, Mittal SC, Kumar A. Evaluation of preinduction scoring systems. ANZJ Obstet Gynecol. 1987;27:309-11.

10. Friedman EA, Niswander KR, Bayonet- Rivera NP, Sachtleben MR. Relationship of prelabor evaluation to inducibility and the course of labor. Obstet Gynecol. 1996;28:459-501.

11. Bouyer J, Papiernik E, Dreyis J, Collin D, Winisdoerffer B, Gueguen S. Maturation signs of the cervix and prediction of preterm birth. Obstet Gynaecol. 1986;68:209-14.

12. Chandra S, Crane JAI, Hutchens D. Transvaginal ultrasound and digital examination in predicting successful labour induction. Obstet Gynecol. 2001;98(1):2-6.

13. Gabriel R, Darnaud T, Chalot F, Gonzalez N, Leymarie F, Quereux C. Transvaginal sonography of the uterine cervix prior to labour induction. Ultrasound Obstet Gynecol. 2002;19:254-7.

14. Daskalakis G, Thomakos N, Hatziioannou L, Mesogitis S, Papantoniou N, Antsaklis A. Sonographic cervical length measurement before labour induction in term nulliparous women. Fetal Diagn Ther. 2006;21(1):34-8. 
15. Rane SM, Pandis GK, Guirgis RR, Higgins B, Nicolaides KH. Pre-induction sonographic measurement of cervical length in prolonged pregnancy: the effect of parity in the prediction of induction to delivery interval. Ultrasound Obstet Gynecol. 2003;22(1):40-8.

16. Yang SH, Roh CR, Kim JH. Transvaginal ultrasonography for cervical assessment before induction of labour. $\mathrm{J}$ Ultrasound Med. 2004;23(3):375-82.

17. Rane SM, Guirgis RR, Higgins B, Nicolaides KH. The value of ultrasound in the prediction of successful induction of labour. Ultrasound Obstet Gynecol. 2004;24:538-549.

18. Boozarjomehri F, Timor-Tritsch I, Chao CR, Fox HE. Presence of cervical wedging is associated with shorter duration of induced labor. Am $\mathbf{J}$ obstet Gynecol. 1994;171:1081-7.

19. Gomez Laencina AM, Sanchez FG, Gimenez JH, Martinez MS, Valverde Martinez JA, Vizcaino VM. Comparison of ultrasonographic cervical length and Bishop in predicting successful labour induction. Acta Obstet Gynecol Scand. 2007;86(7):799-804.
20. Tan PC, Vallikkannu N, Suguna S, Quek KF, Hassan J. Transvaginal sonographic measurement of cervical length versus Bishop's score in labour induction at term: tolerability and prediction of cesarean delivery. Ultrasound Obstet Gynecol. 2007;29(5):568-73.

21. Watson WJ, Stevens D,Welter S, Day D. Factors predicting successful labour induction. Obstet Gynecol. 1996;88:990-2.

22. Gonen R, Degani S, Ron A. Prediction of successful induction of labour: comparison of transvaginal ultrasonography and the Bishop score. Eur J Ultrasound. 1998;7:183-7.

23. Ware V, Raynor D. Transvaginal ultrasonographic cervical measurement as a predictor of successful labour induction. Am J Obstet Gynecol. 2000;182:1030-2.

Cite this article as: Shreya MS, Savitha C.

Significance of transvaginal sonographic assessment of cervical length before induction of labour. Int $\mathbf{J}$ Reprod Contracept Obstet Gynecol 2018;7:3702-6. 